\title{
Isolation, phenotypic characterization and genome wide analysis of a Chlamydomonas reinhardtii strain naturally modified under laboratory conditions: towards enhanced microalgal biomass and lipid production for biofuels
}

Sung-Eun Shin ${ }^{1,3+}$, Hyun Gi Koh ${ }^{1 \dagger}$, Nam Kyu Kang ${ }^{2}$, William I. Suh², Byeong-ryool Jeong ${ }^{1}$, Bongsoo Lee ${ }^{1 *}$ (D) and Yong Keun Chang ${ }^{1,2^{*}}$

\begin{abstract}
Background: Microalgal strain development through genetic engineering has received much attention as a way to improve the traits of microalgae suitable for biofuel production. However, there are still some limitations in application of genetically modified organisms. In this regard, there has been recent interest in the isolation and characterization of superior strains naturally modified and/or adapted under a certain condition and on the interpretation of phenotypic changes through the whole genome sequencing.

Results: In this study, we isolated and characterized a novel derivative of $C$. reinhardtii, whose phenotypic traits diverged significantly from its ancestral strain, C. reinhardtii CC-124. This strain, designated as CC-124H, displayed cell population containing increased numbers of larger cells, which resulted in an increased biomass productivity compared to its ancestor CC-124. CC-124H was further compared with the CC-124 wild-type strain which underwent long-term storage under low light condition, designated as CC-124L. In an effort to evaluate the potential of CC-124H for biofuel production, we also found that CC-124H accumulated 116 and $66 \%$ greater lipids than that of the CC-124L, after 4 days under nitrogen and sulfur depleted conditions, respectively. Taken together, our results revealed that CC-124H had significantly increased fatty acid methyl ester (FAME) yields that were 2.66 and 1.98 times higher than that of the CC-124L at 4 days after the onset of cultivation under N and S depleted conditions, respectively, and these higher FAME yields were still maintained by day 8 . We next analyzed single nucleotide polymorphisms (SNPs) and insertion/deletions (indels) based on the whole genome sequencing. The result revealed that of the 44 CDS region alterations, 34 resulted in non-synonymous substitutions within 33 genes which may mostly be involved in cell cycle, division or proliferation.
\end{abstract}

Conclusion: Our phenotypic analysis, which emphasized lipid productivity, clearly revealed that CC-124H had a dramatically enhanced biomass and lipid content compared to the CC-124L. Moreover, SNPs and indels analysis enabled us to identify 34 of non-synonymous substitutions which may result in phenotypic changes of CC-124H. All

\footnotetext{
*Correspondence: bongsoolee@kaist.ac.kr; changyk@kaist.ac.kr

†Sung-Eun Shin and Hyun Gi Koh contributed equally to this work

${ }^{1}$ Department of Chemical and Biomolecular Engineering, KAIST, 291

Daehak-ro, Yuseong-gu, Daejeon 34141, Republic of Korea

Full list of author information is available at the end of the article
} 
of these results suggest that the concept of adaptive evolution combined with genome wide analysis can be applied to microalgal strain development for biofuel production.

Keywords: Microalgae, Chlamydomonas reinhardtii, Adaptive evolution, Fatty acid methyl ester, Biodiesel, Nitrogen starvation

\section{Background}

Petroleum has been considered to be an irreplaceable source for the production of fuels and chemical materials since the industrial revolution. However, continuous use of fossil fuels has caused many environmental problems and the exhaustion of oil deposits. These problems have raised the necessity to develop new renewable energy sources [1]. In this respect, microalgae have been in the spotlight as a promising feedstock for biofuels and valueadded products due to their high lipid contents and rapid growth through photosynthesis consuming $\mathrm{CO}_{2}$ more efficiently compared to other feedstocks, such as crops and lignocellulosic biomass [1-3].

Among the various microalgae species, green unicellular microalgae, Chlamydomonas reinhardtii, has been intensively studied for over 30 years as a model for basic physiology and applied biotechnology research [4]. Studies in this organism have provided tremendous knowledge for understanding the mechanism behind algal metabolism and for developing molecular tools and techniques for genetic engineering. These information and tools from C. reinhardtii are now being applied to other microalgae as well to maximize biomass and lipid productivity [4-7]. In particular, current efforts have emphasized the production of triacylglycerols (TAGs) that can be used as a substrate for biodiesel production [8]. Since the identification and characterization of starchless mutants in C. reinhardtii, several studies have shown that wild-type (WT) and mutant strains accumulate a significant amount of neutral lipids (TAGs) in response to nitrogen, sulfur or salt stress [9-14]. Meanwhile, there have been other efforts to increase biomass through the genetic engineering of genes which are involved in the photosynthesis of $C$. reinhardtii. The truncated light harvesting antenna complex (tla) mutants have shown an increased biomass compared to their WT strain [1519]. These previous studies suggest that various traits of microalgae including growth and lipid synthesis can be improved through genetic engineering.

However, despite these potentials, there are still some limitations in the use of GMOs and the development of microalgal strains that meet academic and industrial standards for successful biofuel production. These limitations sometimes include genetic redundancy, controversial phenotypes and unstable expression of introduced genes in the genetically engineered strains. Thus far, the most common strategy for enhancing lipid production is likely to express one of the genes involved in TAG synthesis. Unfortunately, however, much greater accumulation of TAG has been rarely guaranteed with this strategy. For instance, targeted overexpression of type 2 diacylglycerol acyltransferases (DGATs) DGTT1, DGTT2 and DGTT3 designated as DGAT2-a, DGAT2c and DGAT2-b, respectively, did not affect TAG accumulation in $C$. reinhardtii [20], while overexpression of DGTT1 and DGTT3 designated as DGAT2-5 and DGAT2-1 led to increased TAG accumulation [21]. This indicates that not only it is difficult to expect increased TAG accumulation even with overexpression of one gene which plays an important role in TAG biosynthesis, but also different phenotypes can be exhibited even in strains modified with the same target genes. In addition to these problems, unstable expression in transgenic strains has long been reported in higher plants and C. reinhardtii [22-25]. This may ultimately result in the loss of phenotypes making it difficult for researchers to use genetically engineered strains for biofuel production.

Microalgae are ubiquitous microorganisms present in almost all the ecosystems implying that microalgae may have naturally developed their favorable traits through environmental adaptations [7]. In this context, strain development of $C$. reinhardtii through experimental adaptive evolution has succeeded in its efforts to improve their growth, lipid content, photosynthetic efficiency, $\mathrm{CO}_{2}$ utilization efficiency and heterotrophy, respectively [26-29]. Moreover, single nucleotide polymorphisms (SNPs) or insertions/deletions (indels) analysis using progressive and large-scale sequencing called next-generation sequencing (NGS) technologies have provided new insights for the identification of sequence variations within the individual genomes and for the interpretation of mutant phenotypes [26, 30-34]. These suggest that an adaptive evolution strategy combined with NGS technology could be an alternative method to circumvent the regulations on the use of GMOs and the current limitations of genetic engineering for microalgal strain development.

One major difference between the natural adaptive evolution and intentional adaptive evolution is the presence and absence of selection pressure. While the presence of selection pressure that comes with intentional adaptive evolution may increase the likelihood 
of obtaining a strain with desired characteristics, there is also a greater probability for the culture to lose that desired trait if that selection pressure is removed, as the wild-type strain may regain fitness advantage against the mutant. In this study, we isolated naturally, but not intentionally adapted C. reinhardtii CC-124 during cell maintenance under laboratory conditions. The phenotypic traits of this strain designated as $\mathrm{CC}-124 \mathrm{H}$ were visibly distinct from its ancestral WT strain. To characterize the phenotypic changes in $\mathrm{CC}-124 \mathrm{H}$ and to further assess the potential application of $\mathrm{CC}-124 \mathrm{H}$ for biofuel production, we analyzed the biomass, FAME contents and biochemical components of the WT and CC- $124 \mathrm{H}$ strains under normal and nutrient stress conditions such as $\mathrm{N}$ and $\mathrm{S}$ deprivation. In addition, we performed whole genome sequencing and SNPs/indels analysis to identify sequence variations and to understand phenotypic changes in the CC-124H strain.

\section{Results}

\section{Isolation of the CC-124H strain}

During the process of maintaining the $C$. reinhardtii CC-124 strain, in which colonies were regularly transferred onto fresh TAP agar plates once every month for approximately 4 years and incubated at $25{ }^{\circ} \mathrm{C}$ under a continuous fluorescent light condition $(120 \mu \mathrm{mol}$ photons $/ \mathrm{m}^{2} / \mathrm{s}$ ), we found that the growth rate of the C. reinhardtii CC-124 strain became faster compared to the last 4 years. When the initial cell concentration of the inoculum was adjusted to $0.1 \mathrm{OD}_{750}$, the dry cell weight (DCW) of the C. reinhardtii CC-124 strain measured in 2015 reached $0.72 \mathrm{~g} / \mathrm{L}$ after $24 \mathrm{~h}$ of growth, which was about three and four times greater than those measured in 2013 and 2010, respectively (Fig. 1). Moreover, the specific growth rate during the exponential phase but not the stationary phase was more rapid (Additional file 1: Table S1), indicating that the physiological phenotype of the $C$. reinhardtii CC-124 strain, especially for growth related to biomass production, may have been naturally altered under laboratory conditions over the 4 years. The mutant had also exhibited loss of mobility, no flagella, and lacks the negative phototaxis that is normally found in the wild-type cells, as well as substantial increase of the proportion of cells in the palmelloid state. To further understand the physiological change and evaluate the potential as a source for biofuel production, a C. reinhardtii CC-124 strain with a better trait for biomass production was isolated and designated as CC-124H. For the subsequent experiment, CC- $124 \mathrm{H}$ was compared with the wild-type strain that was kept for long-term storage in slant culture tubes under low light condition, designated CC-124L.



Fig. 1 Growth comparison of C. reinhardtii in year 2010, 2013, and 2015. Cells were cultivated in liquid TAP medium. Data are expressed as $\pm \mathrm{SD}(n=3)$

\section{Growth of CC-124H under normal conditions}

We first analyzed the growth traits of CC-124L and CC$124 \mathrm{H}$, including cell number, $\mathrm{OD}_{750}$ and $\mathrm{DCW}$ under normal conditions. Our results revealed that the growth rate of $\mathrm{CC}-124 \mathrm{H}$ based on the $\mathrm{OD}_{750}$ and $\mathrm{DCW}$ was continuously higher than that of the CC-124L over the whole cultivation, while the growth rate based on cell number was lower (Fig. 2a-c). In particular, the DCW of $\mathrm{CC}-124 \mathrm{H}$ at 24 and $72 \mathrm{~h}$ was approximately 74 and $13 \%$ greater than that of the CC-124L, respectively (Fig. 2c). Moreover, the specific growth rate of CC-124H based on the DCW at the early period (from 0 to $24 \mathrm{~h}$ ) was 1.34 times higher compared with the CC-124L (Table 1). To investigate the reason behind the increased biomass accumulation in $\mathrm{CC}-124 \mathrm{H}$, we next measured the cell size at $24 \mathrm{~h}$ representing the exponential phase and at $72 \mathrm{~h}$ representing the stationary phase (Table 1 and Additional file 2: Figure S1). The result showed that CC$124 \mathrm{H}$ displays a population with average particle size measurements that were 30 and $26 \%$ bigger than that of CC-124L on average at 24 and $72 \mathrm{~h}$, respectively. We also analyzed the nutrient consumption rate in the CC$124 \mathrm{~L}$ and $\mathrm{CC}-124 \mathrm{H}$ to understand how nutrient uptake is associated with their proliferation and biomass production (Table 1). It should be noted that even though the cell number of CC-124H was constantly lower than that of the CC-124L during the cultivation, the growth rate based on cell counting remained the same as the CC124L except between 12 and $24 \mathrm{~h}$ (Fig. 2a). Our nutrient analysis revealed that the average consumption rate of nutrients including acetate, $\mathrm{NH}_{4}{ }^{+}$and $\mathrm{PO}_{4}{ }^{2-}$ in $\mathrm{CC}-124 \mathrm{H}$ was at the same level as the CC-124L. Interestingly, however, $\mathrm{CC}-124 \mathrm{H}$ utilized much more acetate as a carbon 

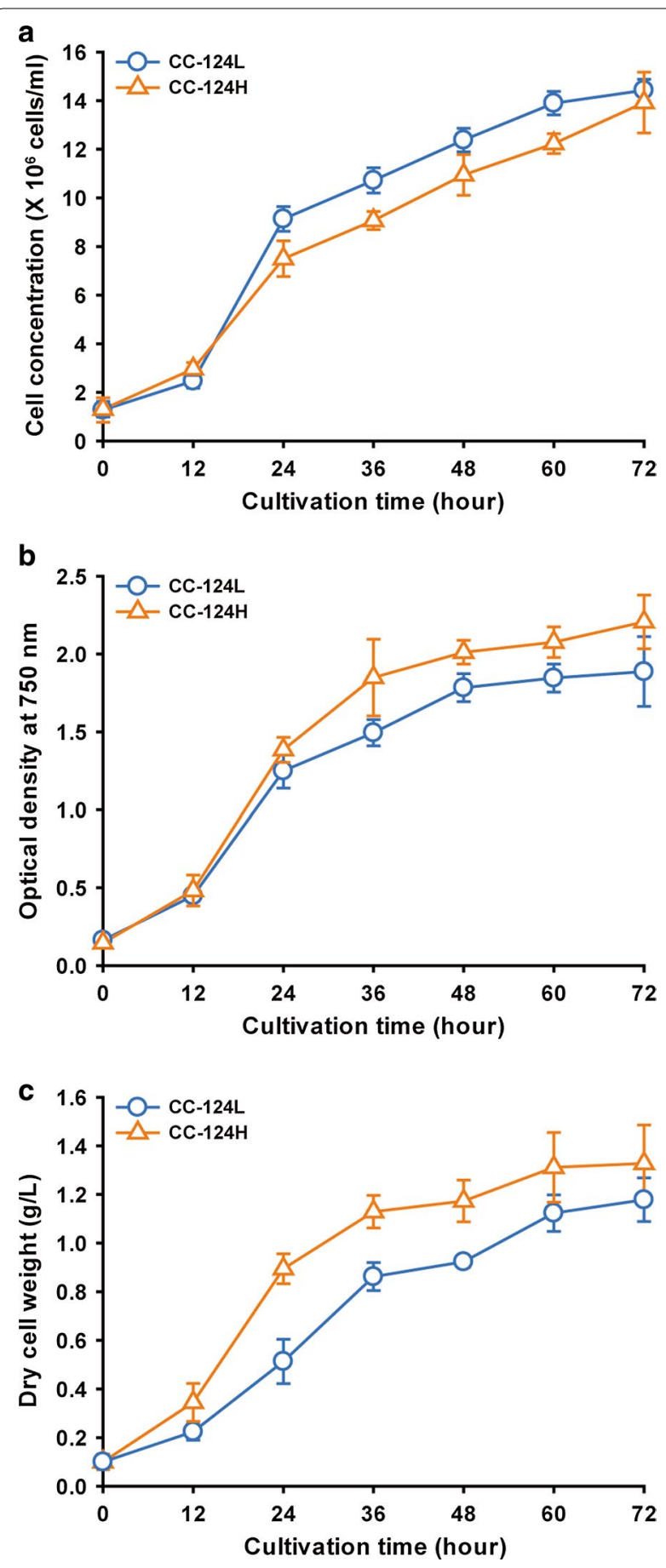

Fig. 2 Growth analyses of CC-124H in liquid TAP medium. Growth curves based on cell density (a), optical density at $750 \mathrm{~nm}(\mathbf{b})$, and dry cell weight (c) were obtained during $72 \mathrm{~h}$. Data are expressed as $\pm \operatorname{SD}(n=4)$

source and $\mathrm{NH}_{4}{ }^{+}$as a nitrogen source by $24 \mathrm{~h}$ compared with the CC-124L (Table 1). This may be interpreted as $\mathrm{CC}-124 \mathrm{H}$ used much more carbon and nitrogen source for efficient proliferation and maintenance of the larger cells especially at the exponential phase based on the experimental evidence that the population of $\mathrm{CC}-124 \mathrm{H}$ at the exponential phase contains much bigger cells compared with that at the stationary phase (Additional file 2: Figure S1). Taken together, these results suggest that the newly isolated $\mathrm{CC}-124 \mathrm{H}$ has significantly distinct phenotypes apart from the CC-124L.

\section{Biomass and FAME analyses of CC-124H under nitrogen and sulfur starvation}

To assess if CC-124H can be used as a biomass source for biofuel production, we analyzed the biomass and FAME of the CC-124L and CC-124H under nitrogen $(\mathrm{N})$ or sulfur (S) starvation conditions (Fig. 3 and Table 2), because previous studies have shown that $C$. reinhardtii can accumulate a significant amount of lipids in response to $\mathrm{N}$ or S deprivation [12-14]. Cultivation of the CC-124L and $\mathrm{CC}-124 \mathrm{H}$ under $\mathrm{N}$ or $\mathrm{S}$ starvation conditions was performed by following modified protocols from previous studies [13, 35]. Briefly, cells grown to exponential phase were harvested and washed twice with the appropriate TAP medium depending on the culture conditions (TAP, TAP without $\mathrm{N}$ and TAP without $\mathrm{S}$ ). Then, the cells whose $\mathrm{OD}_{750}$ was approximately 0.7 were inoculated into the TAP medium without $\mathrm{N}$ and $\mathrm{S}$, respectively. In agreement with the previous studies, lipids in both the CC-124L and CC-124H were induced in response to the $\mathrm{N}$ and $\mathrm{S}$ deprivation (Fig. 3). Interestingly, however, CC$124 \mathrm{H}$ had a significant increase in FAME contents that was approximately twofold higher than that of CC-124L at both 4 and 8 days after the onset of cultivation under $\mathrm{N}$ and $\mathrm{S}$ deprivation conditions, respectively (Fig. 3b, c), while additive FAME production was not induced under normal conditions over the cultivation (Fig. 3a). This implies that the lipid accumulation mechanism of $\mathrm{CC}-124 \mathrm{H}$ in response to $\mathrm{N}$ or S depletion was likely altered from CC-124L. We also analyzed the biomass production of CC-124L and CC-124H (Fig. 3). It should be noted that nutrient stress conditions including $\mathrm{N}$ and $\mathrm{P}$ sources result in a low level of mass production, and biomass production is inversely proportional with the amount of lipid contents, because cells use a lot of energy for growth events such as cell division rather than lipid accumulation [36]. However, interestingly, our biomass analysis result revealed that the DCW of CC-124H at 8 days was $30 \%$ greater than that of CC-124L even under $\mathrm{N}$ starvation (Fig. $3 \mathrm{~b}$ ), whereas there was no significant difference in biomass production under $\mathrm{S}$ starvation condition after 4 days of cultivation (Fig. 3c). Eventually, the higher biomass production combined with the increased FAME contents of $\mathrm{CC}-124 \mathrm{H}$ in response to $\mathrm{N}$ deprivation resulted in a much higher FAME yield that was 2.66 
Table 1 Specific growth rate, cell size, and nutrient consumption rate of CC-124L and CC-124H under normal condition

\begin{tabular}{|c|c|c|c|c|c|c|c|c|c|c|}
\hline \multirow[t]{3}{*}{ Strain } & \multirow{2}{*}{\multicolumn{2}{|c|}{ Specific growth rate $(\mathrm{mg} / \mathrm{mL} / \mathrm{h})^{\mathrm{a}}$}} & \multirow{2}{*}{\multicolumn{2}{|c|}{ Cell size $(\mu \mathrm{m})^{\mathbf{b}}$}} & \multicolumn{6}{|c|}{ Average rate of nutrient consumption $(\mathrm{ppm} / \mathrm{h})^{\mathrm{c}}$} \\
\hline & & & & & \multicolumn{3}{|c|}{$0-24 \mathrm{~h}$} & \multicolumn{3}{|c|}{$0-72 \mathrm{~h}$} \\
\hline & $0-24 \mathrm{~h}$ & $24-72 \mathrm{~h}$ & $24 \mathrm{~h}$ & $72 \mathrm{~h}$ & $C$ & $N$ & $P$ & $C$ & $N$ & $P$ \\
\hline CC-124L & $0.070 \pm 0.015$ & $0.018 \pm 0.003$ & $7.16 \pm 0.01$ & $7.30 \pm 0.01$ & 22.90 & 2.47 & 1.39 & 13.90 & 1.34 & 1.20 \\
\hline $\mathrm{CC}-124 \mathrm{H}$ & $0.094 \pm 0.014^{*}$ & $0.008 \pm 0.001^{* *}$ & $9.36 \pm 0.11$ & $9.24 \pm 0.02$ & 33.10 & 3.20 & 1.14 & 13.90 & 1.32 & 0.77 \\
\hline
\end{tabular}

Data are expressed as $\pm \mathrm{SD}(n=4)$. Significant differences, as determined by Student's $t$ test, are indicated by asterisk $\left(* P<0.05,{ }^{* *} P<0.01,{ }^{* * *} P<0.001\right)$

a Specific growth rate based on dry cell weight was calculated as following equations: Specific growth rate $(\mu /$ day $)=\ln \left(X_{2} / X_{1}\right) /\left(T_{2}-T_{1}\right)$, where $X_{1}$ and $X_{2}$ are the initial and final dry cell weight, and $T_{1}$ and $T_{2}$ are the initial and final times

b Cell size measured among the $50 \%$ in the middle value

c Nutrient consumption was based on acetate for $C$, ammonium for $N$, and phosphate for $P$ sources
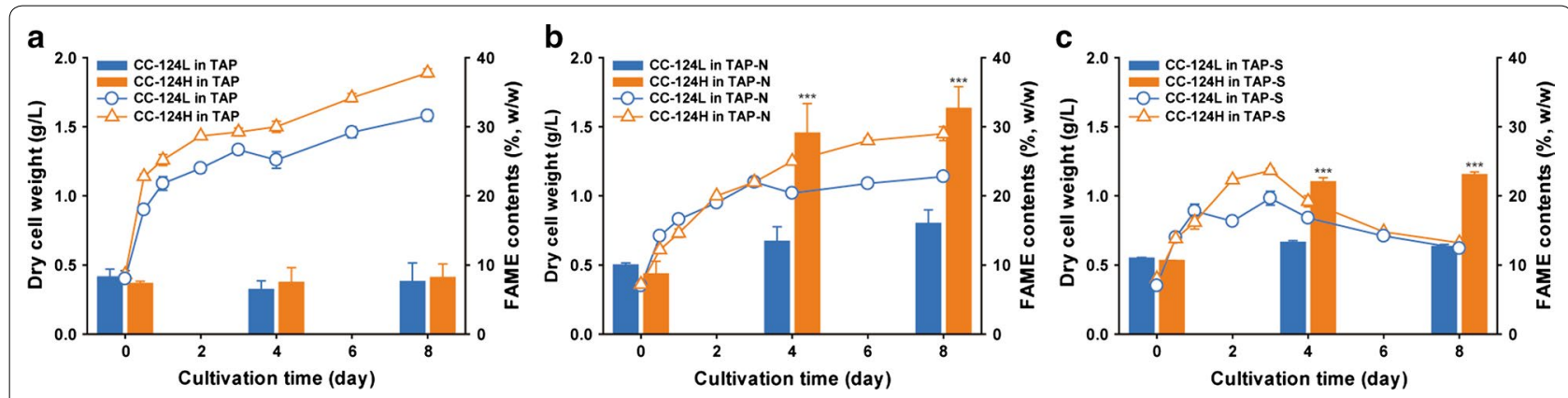

Fig. 3 Biomass and lipid production of CC-124H under different nutrient starved conditions. Cells were cultivated under normal conditions (a), $\mathrm{N}$ starvation (b), and S starvation (c). Lines and bars each indicate the DCW and the FAME contents at different cultivation conditions. Data are expressed as \pm SD $(n=4)$. Significant differences, as determined by Student's $t$ test, are indicated by asterisk $\left({ }^{*} P<0.05,{ }^{* *} P<0.01,{ }^{* * *} P<0.001\right)$

Table 2 Biomass and FAME of CC-124H under nutrient starvation condition

\begin{tabular}{|c|c|c|c|c|c|c|c|}
\hline \multirow[t]{2}{*}{ Time (day) } & \multirow[t]{2}{*}{ Culture } & \multicolumn{3}{|l|}{ CC-124L } & \multicolumn{3}{|l|}{ CC-124H } \\
\hline & & Biomass (g/L) & FAME contents (\%) & FAME yield (mg/L) & Biomass (g/L) & FAME contents (\%) & FAME yield (mg/L) \\
\hline \multirow[t]{3}{*}{0} & TAP & $0.38 \pm 0.03$ & $8.26 \pm 1.13$ & $32.29 \pm 5.15$ & $0.41 \pm 0.04$ & $7.30 \pm 1.74$ & $29.98 \pm 9.15$ \\
\hline & TAP-N & $0.38 \pm 0.03$ & $10.05 \pm 0.31$ & $36.25 \pm 3.48$ & $0.39 \pm 0.03$ & $9.10 \pm 1.76$ & $34.95 \pm 9.04$ \\
\hline & TAP-S & $0.37 \pm 0.02$ & $10.97 \pm 0.13$ & $40.59 \pm 2.71$ & $0.39 \pm 0.02$ & $10.63 \pm 0.03$ & $41.97 \pm 2.25$ \\
\hline \multirow[t]{3}{*}{4} & TAP & $1.19 \pm 0.09$ & $6.44 \pm 1.26$ & $80.13 \pm 18.12$ & $1.42 \pm 0.09^{* *}$ & $7.46 \pm 0.92$ & $108.88 \pm 16.39^{*}$ \\
\hline & TAP-N & $0.97 \pm 0.05$ & $14.15 \pm 2.24$ & $141.04 \pm 20.16$ & $1.22 \pm 0.04^{* * *}$ & $30.50 \pm 4.42^{* * *}$ & $374.54 \pm 51.72^{* *}$ \\
\hline & TAP-S & $0.82 \pm 0.02$ & $13.24 \pm 0.29$ & $108.63 \pm 4.79$ & $0.98 \pm 0.03^{* * *}$ & $22.01 \pm 0.60^{* * *}$ & $214.79 \pm 12.27^{* * *}$ \\
\hline \multirow[t]{3}{*}{8} & TAP & $1.46 \pm 0.12$ & $7.58 \pm 2.73$ & $115.38 \pm 38.74$ & $1.74 \pm 0.15^{*}$ & $8.18 \pm 1.79$ & $147.58 \pm 29.41$ \\
\hline & TAP-N & $1.11 \pm 0.04$ & $16.14 \pm 1.68$ & $180.35 \pm 15.69$ & $1.44 \pm 0.04^{* * *}$ & $33.49 \pm 3.16^{* * *}$ & $477.89 \pm 36.43^{* * *}$ \\
\hline & TAP-S & $0.57 \pm 0.05$ & $12.66 \pm 0.32$ & $72.74 \pm 5.92$ & $0.64 \pm 0.03$ & $23.07 \pm 0.41^{* * *}$ & $150.15 \pm 7.07^{* * *}$ \\
\hline
\end{tabular}

Data are expressed as $\pm \mathrm{SD}(n=4)$. Significant differences, as determined by Student's $t$ test, are indicated by asterisk $\left({ }^{*} P<0.05,{ }^{* *} P<0.01,{ }^{* * *} P<0.001\right)$

and 2.65 times greater than that of the CC-124L after 4 and 8 days under $\mathrm{N}$ depleted conditions, respectively (Table 2). To elucidate the highly induced lipid accumulation of $\mathrm{CC}-124 \mathrm{H}$ in vivo, we next performed microscopic analysis which is able to visualize lipid bodies accumulated in response to $\mathrm{N}$ or $\mathrm{S}$ starvation (Fig. 4). Consistent with the FAME result, our analysis revealed that the CC-124H cells under $\mathrm{N}$ and S depleted conditions, especially grown in TAP medium without $\mathrm{N}$ source, clearly had much bigger and/or numerous lipid bodies compared to the CC-124L cells grown in normal conditions, when observing both under a confocal microscope and transmission electron microscope (TEM) (Fig. 4a, b). To sum up, the results from our biomass and FAME analyses clearly revealed that $\mathrm{CC}-124 \mathrm{H}$ can produce a large amount of lipids as well as biomass compared with the 


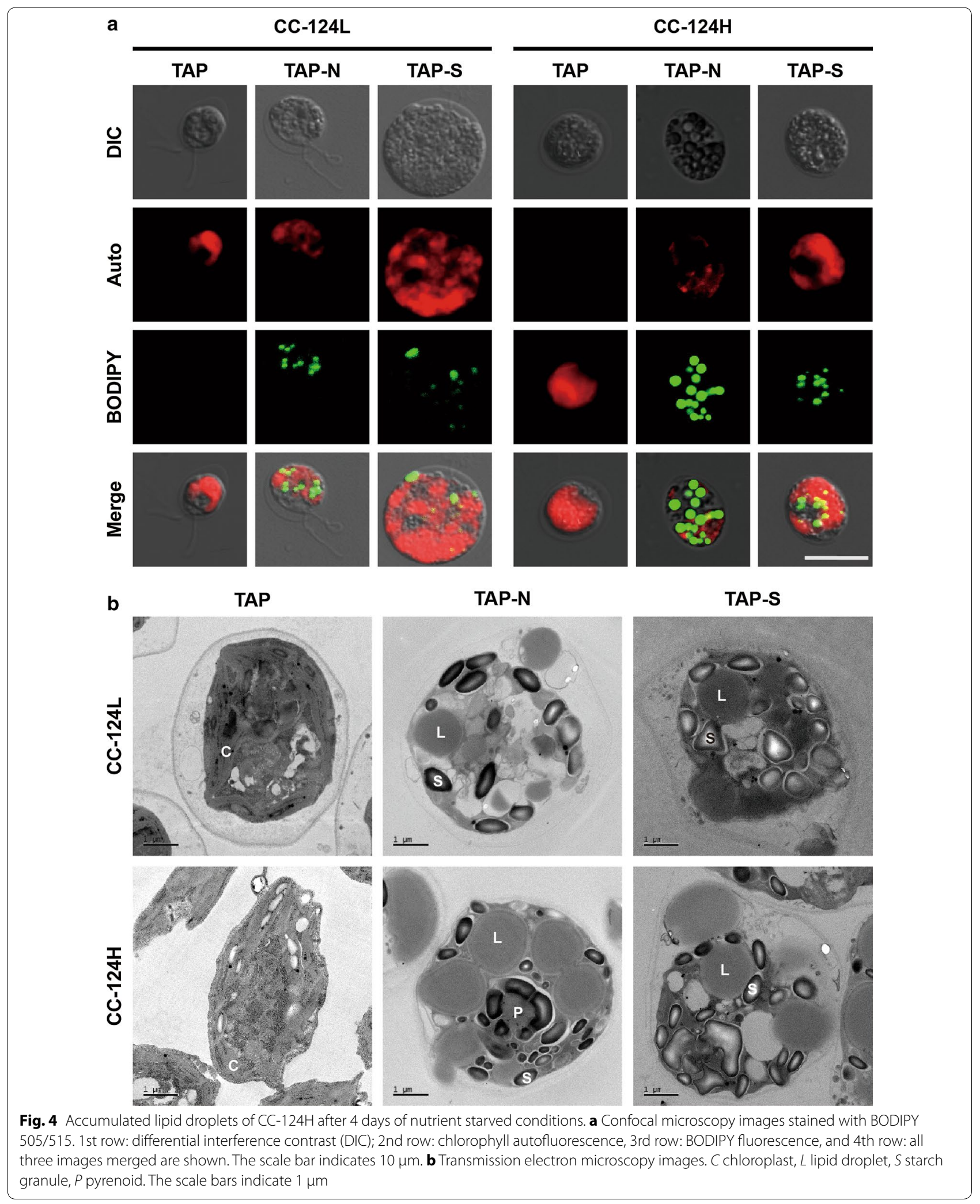


CC-124L and further suggest that more studies on CC$124 \mathrm{H}$ may provide us important insights to elucidate the mechanisms behind the relationship between lipid accumulation and growth under $\mathrm{N}$ depleted conditions as well as normal conditions.

\section{Carbohydrate, protein and chlorophyll quantification}

It has long been proposed that photosynthetic microalgae fix carbon, and these photosynthetically fixed carbons are transformed into major reserve macromolecules such as lipids, carbohydrates and proteins through a carbon assimilation and partitioning mechanism [37]. To further understand the mechanism underlying the significantly increased lipids in CC- $124 \mathrm{H}$ and the corresponding changes of the biochemical compositions, we also analyzed the carbohydrate, protein and chlorophyll levels of the CC-124L and CC-124H grown under $\mathrm{N}$ and $\mathrm{S}$ depleted conditions, respectively (Fig. 5). Our results showed that CC-124H accumulated greater quantities of carbohydrates more rapidly compared to that of CC-124L during cultivation under both normal and $\mathrm{S}$ depleted conditions. Interestingly, however, CC-124H accumulated carbohydrates to a much lesser extent under $\mathrm{N}$ depleted conditions compared to CC-124L, which still contained a significant amount of carbohydrates under the same conditions. Finally, both the protein and chlorophyll contents were found to be decreased when the cultures were subjected to $\mathrm{N}$ and $\mathrm{S}$ depleted conditions as expected. However, CC-124H showed far lower levels of protein and chlorophyll contents compared to that of the CC-124L in the N and S depleted media. In particular, the extent of reduction in chlorophyll contents was particularly striking in the case of CC- $124 \mathrm{H}$ under the S depleted conditions, because the culture was nearly devoid of chlorophyll and white in appearance (Fig. 5).

\section{Whole genome sequencing and SNPs/indels analysis}

To investigate the variation of $\mathrm{CC}-124 \mathrm{H}$ in a genome level and understand the significant phenotypic changes of CC- $124 \mathrm{H}$ in biomass and FAME production, we performed whole genome sequencing and SNPs/indels analysis of the CC-124L and CC-124H. A schematic workflow of the genome sequencing and SNPs/indels analysis is summarized in the Additional file 3: Figure S2. After filtering was done to remove low-quality sequence, the average coverage of the genome was $25.95 \times$ and $31.03 \times$ in the CC-124L and CC-124H, respectively. We obtained approximately $95 \%$ of the mapping region in both CC$124 \mathrm{~L}$ and CC-124H sequencing data after alignment to the C. reinhardtii reference genome v5.5 (Phytozome ver 10.1). Our analysis revealed that there were 29,222 and $28,599 \mathrm{SNPs} /$ indels in the CC-124L and CC-124H, respectively, when compared to the reference genome. In an effort to identify polymorphisms and indels specific to CC- $124 \mathrm{H}$, we found a total of $369 \mathrm{SNPs} /$ indels comprising of 256 SNPs and 113 indels against the CC-124L. For the 369 SNPs/indels, 90\% of them (331 SNPs/indels) occurred in genic regions which can possibly affect the function of proteins as follows: 253 SNPs/indels (76\%) were in introns, 35 (11\%) in untranslated regions (UTRs), and $44(13 \%)$ in coding sequence (CDS) regions (Fig. 6a). The subsequent analysis revealed that of the 44 alterations in CDS regions, 34 gave rise to non-synonymous substitutions within 33 genes, while ten led to synonymous substitutions in ten genes. CDS regions that resulted in non-synonymous substitutions were blasted with the annotated protein and homologous information of Arabidopsis thaliana using the TAIR10 database (the Arabidopsis Information Resource, https://www.arabidopsis. org/). Nineteen annotated genes that were found to have substitutions in the CDS regions are listed in Table 3. For sensitive analysis, the GSEA (Gene Set Enrichment
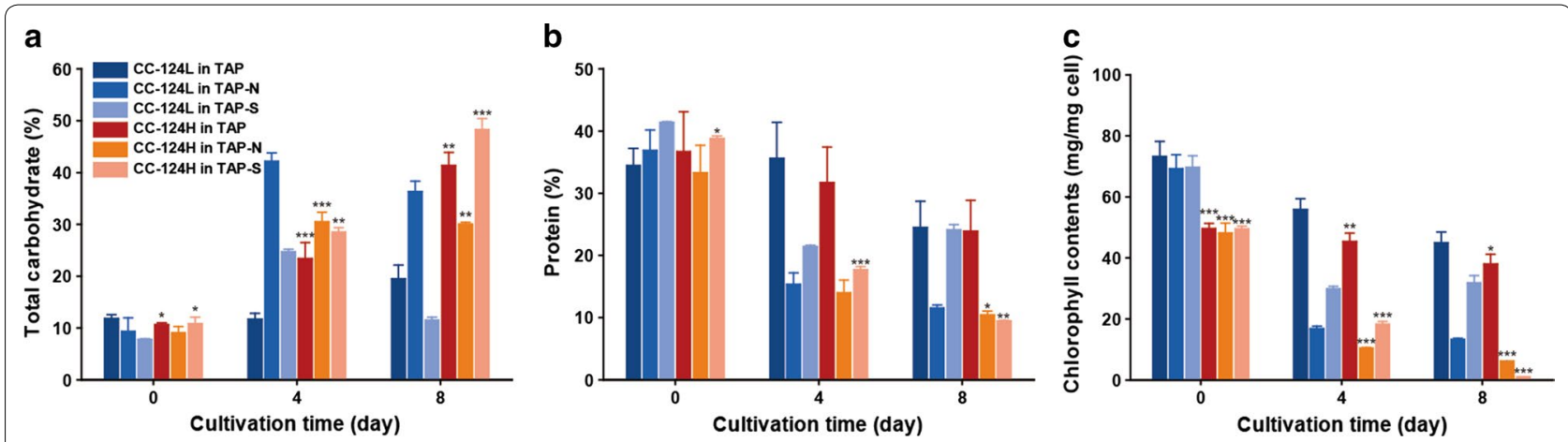

Fig. 5 Biochemical composition and chlorophyll content changes of CC-124H under N and S starvation. Total carbohydrate (a), protein (b) and chlorophyll (c) contents were measured at 0,4 , and 8 days of induction. Data are expressed as $\pm \operatorname{SD}(n=4)$. Significant differences, as determined by Student's $t$ test, are indicated by asterisk $\left({ }^{*} P<0.05,{ }^{* *} P<0.01,{ }^{* *} P<0.001\right)$ 

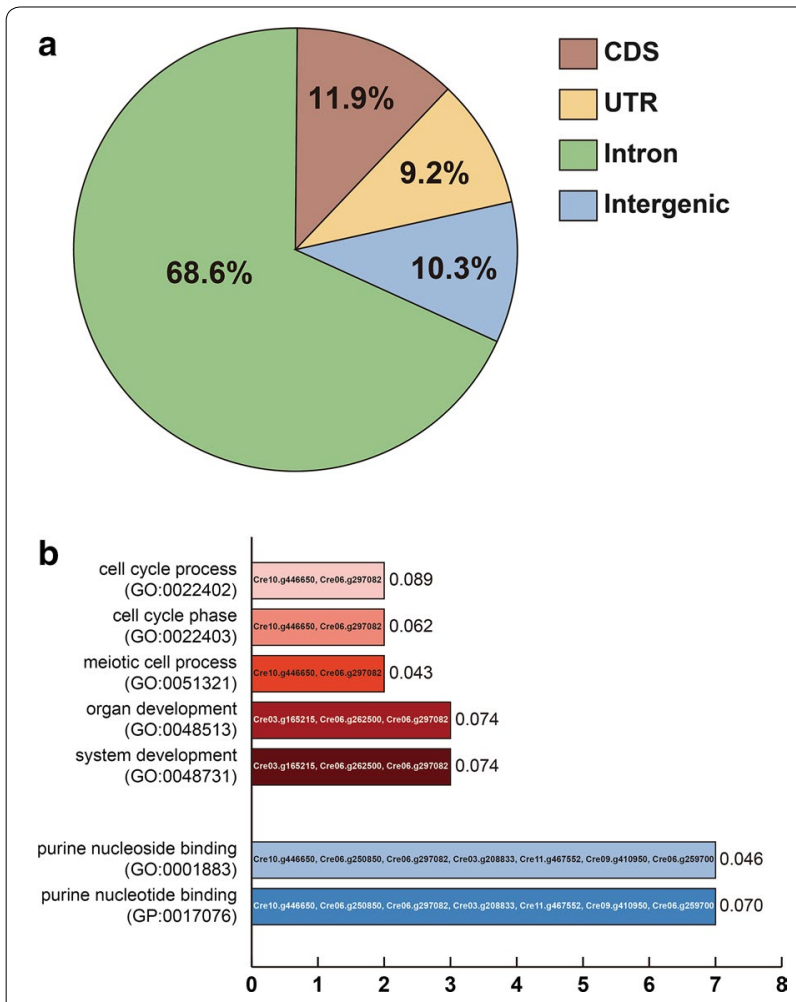

Fig. 6 SNP/indels and GSEA of CC $-124 \mathrm{H}$ a the locational pattern of single polymorphisms (SNPs) and insertion/deletion (indels) between CC-124H and CC-124L. b GSEA (GSEA) analysis by gene ontology (GO) depth 3. 19 non-synonymous genes in CDS regions were annotated by TAIR10 database, and the sensitivity test was conducted by gene set enrichment (GSEA) methods. Nine annotated genes remained, and the $P$ value for each gene was calculated by Fisher's exact test. The $P$ value, GO term and phytozome locus name of $C$. reinhardtii were indicated in each column. The top five columns belong to the biological process domain, which are displayed in red colors. The below two columns in blue colors are molecular function domain

Analysis) method was used to interpret the distinct phenotype differences [38]. Each gene was categorized by GO terms (Gene Ontology, https://www.geneontology. org/) at depth of three, which are shown in Fig. 6b. Based on the results of the GSEA analysis, nine annotated genes were categorized into two domains (molecular function and biological process) and were subdivided into seven GO terms (Fig. 6b). Most of the GO terms were found to be involved with molecular function and were specialized for purine nucleoside/nucleotide binding. In the biological process domain, Cre10g.446650 and Cre06.g297082 were identified as genes related with cell division and cell cycle regulation. It is speculated that continuous illumination over extended periods of time was the possible cause behind the mutations in those genes within CC$124 \mathrm{H}$. These mutations could have caused alterations within the cell cycle of CC- $124 \mathrm{H}$, which could explain the faster growth under normal conditions and higher lipid accumulation under nutrient stress.

\section{Discussion}

There are growing interests in microalgal strain development through genetic manipulation for enhancing their biomass and lipid productivity [39]. Moreover, the systems and methods used for large-scale outdoor cultivation of microalgae have been developed and tested with various microalgal species, and these efforts have elucidated the potential for economically feasible biofuel production from microalgae $[40,41]$. Therefore, outdoor mass cultivation techniques coupled with strain development through genetic manipulation of metabolic networks may eventually be needed to realize a successful commercialization of microalgae-based biofuel production. Unfortunately, however, there are still constraints in the use of genetically modified microalgae in an outdoor cultivation system due to safety concerns [31, 42]. Some researchers have pointed out that the biosafety issue of GMOs should be addressed before they are introduced into the environment [42-44]. In this context, forward genetics approaches have been applied in the microalgae field to generate non-GMOs that show enhanced traits in terms of biomass and lipid production as well as stress tolerance [11, 28, 31, 45]. Moreover, it has been proposed that experimental evolution can be an alternative strategy to circumvent public misgivings about the cultivation of genetically modified microalgae in an outdoor system [42]. It is known that adaptive evolution caused by an accumulation of mutations conferring selective advantages against particular environment conditions can lead a new generation which possess novel traits [46-48].

In the present study, we isolated $\mathrm{CC}-124 \mathrm{H}$ which likely adapted to the laboratory conditions. Although this strain was not intentionally obtained through experimental evolution, the growth trait of the CC-124H strain based on the DCW is visibly distinct from its WT strain CC-124 compared to 5 years ago (Fig. 1), and the high biomass productivity is linked with the cell population of $\mathrm{CC}-124 \mathrm{H}$ containing relatively larger cells compared to the CC-124L (Additional file 2: Figure S1). Although $\mathrm{CC}-124 \mathrm{H}$ exhibited superior growth rate in terms of optical density and DCW compared to CC-124L, (Fig. 2) the difference in the growth profile between $\mathrm{CC}-124 \mathrm{H}$ and $\mathrm{CC}-124 \mathrm{~L}$ is not as great in comparison to the difference between CC-124H and the ancestral CC-124 strain from 5 years ago. It should be noted that CC-124L is the CC-124 strain that has been kept for 5 years in slant culture tube under low light condition. Since CC-124L was under long-term storage in the slant and was rarely retransferred into a new agar slant, it obviously underwent a far smaller number of division cycles in comparison to 
Table 3 CC-124H specific genomic DNA information of single polymorphisms (SNPs) and insertion/deletion (indels)

\begin{tabular}{|c|c|c|c|c|c|c|}
\hline $\mathrm{chr}^{\mathrm{a}}$ & Position & Type & Genic & Feature & TAIR10.gene_ID ${ }^{b}$ & TAIR10.desc \\
\hline 1 & 7296452 & SNP & Cre01.g052650 & CDS & AT3G01310.2 & Phosphoglycerate mutase-like family protein \\
\hline 3 & 8957195 & Indel & Cre03.g208833 & CDS & AT1G35530.2 & DEAD/DEAH box RNA helicase family protein \\
\hline 3 & 8972552 & Indel & Cre03.g209281 & CDS & AT1G08190.1 & Vacuolar protein sorting 41 \\
\hline 3 & 3163671 & SNP & Cre03.g165215 & CDS & AT5G45900.1 & ThiF family protein \\
\hline 3 & 4595120 & SNP & Cre03.g177007 & CDS & AT5G63080.1 & 2-Oxoglutarate (2OG) and Fe(II)-dependent oxygenase superfamily protein \\
\hline 6 & 82060 & Indel & Cre06.g249500 & CDS & AT4G14140.1 & DNA methyltransferase 2 \\
\hline 6 & 262541 & Indel & Cre06.g250850 & CDS & AT3G24320.1 & MUTL protein homolog 1 \\
\hline 6 & 408975 & Indel & Cre06.g252100 & CDS & AT5G58410.1 & HEAT/U-box domain-containing protein \\
\hline 6 & 1502181 & Indel & Cre06.g259700 & CDS & AT3G52570.1 & Alpha/beta-Hydrolases superfamily protein \\
\hline 6 & 1804583 & Indel & Cre06.g262500 & CDS & AT4G24560.1 & Ubiquitin-specific protease 16 \\
\hline 6 & 2321106 & SNP & Cre06.g267250 & CDS & AT3G23610.3 & Dual specificity protein phosphatase 1 \\
\hline 6 & 5727069 & SNP & Cre06.g286950 & CDS & AT3G04710.1 & Ankyrin repeat family protein \\
\hline 6 & 7089219 & SNP & Cre06.g297082 & CDS & AT5G07280.1 & Leucine-rich repeat transmembrane protein kinase \\
\hline 9 & 6439357 & Indel & Cre09.g407110 & CDS & AT5G19840.2 & 2-oxoglutarate (2OG) and Fe(II)-dependent oxygenase superfamily protein \\
\hline 9 & 5152546 & SNP & Cre09.g399030 & CDS & AT1G06570.1 & phytoene desaturation 1 \\
\hline 9 & 5224176 & SNP & Cre09.9399439 & CDS & AT5G19080.1 & RING/U-box superfamily protein \\
\hline 9 & 7001422 & SNP & Cre09.9410950 & CDS & AT1G37130.1 & Nitrate reductase 2 \\
\hline 9 & 7399225 & SNP & Creg09.g413200 & CDS & AT1G03740.1 & Protein kinase superfamily protein \\
\hline 10 & 3763671 & SNP & Cre10.g446650 & CDS & AT3G27730.1 & ATP binding; ATP-dependent helicases; DNA helicases \\
\hline 11 & 222386 & Indel & Cre11.g467552 & CDS & AT2G22480.1 & Phosphofructokinase 5 \\
\hline
\end{tabular}

a Chromosome number in Chlamydomonas reinhardtii

b Gene ID in Arabidopsis thaliana homologous with genes in C. reinhardtii

c Description of TAIR10.gene_ID

$\mathrm{CC}-124 \mathrm{H}$, and it is thought to be genetically close to the ancestral CC-124. However, it is unlikely that CC-124L is genetically identical to its CC-124 ancestor, and this may explain the slightly enhanced performance of CC-124L compared to its ancestor.

Traditionally, C. reinhardtii has not been known as an oleaginous species [35]. On the other hand, it has also been reported that the average lipid content of C. reinhardtii is comparable to that of other microalgae species, and the natural level of lipid contents can widely vary even among C. reinhardtii strains $[9,41]$. More recently, Nakanishi et al. suggested that $C$. reinhardtii JSC4 isolated from the ocean accumulates a significant amount of lipids indicating that it also has potential to be used as industrial strain for biofuel production [49]. Current studies on microalgal strain development have mainly focused on both biomass and lipid production, as the overall lipid productivity is based on these two factors. In general, the lipid content increases under nutrient stress conditions such as $\mathrm{N}$ or $\mathrm{S}$ starvation, while the growth rate declines in C. reinhardtii [12-14]. In fact, several studies have provided clues to elucidate the mechanism behind the lipid accumulation in response to $\mathrm{N}$ deprivation. $\mathrm{N}$ deprivation led to the downregulation of genes for components of photosynthesis and the upregulation of genes for fatty acid biosynthesis [50, 51]. In addition, a time course transcriptome analysis of C. reinhardtii revealed that the gene cluster involved in lipid metabolism was highly expressed during the lipid accumulation phase, whereas photosynthesis related genes which play a crucial role in cell proliferation were downregulated during the stationary phase [52]. In Nannochloropsis sp., which is currently considered as a model microalga for biofuel production, genes associated with energy metabolism were downregulated in response to $\mathrm{N}$ starvation $[53,54]$. These imply that there is an inverse relationship between the expression patterns of genes responsible for lipid metabolism and cell proliferation, and thus growth and lipid accumulation events are rarely synchronized during microalgae cultivation [55-57].

In agreement with the previous studies, we observed that the FAME content of the CC-124L gradually increased in response to $\mathrm{N}$ or $\mathrm{S}$ deprivation, while the amount of biomass was reduced during the cultivation (Fig. 3a-c). Interestingly, however, CC-124H had a significantly enhanced FAME yield that was approximately 2.5 -fold greater than that of CC-124L under $\mathrm{N}$ depleted conditions, and this was further verified through the lipid 
body staining assay and electron microscopy (Figs. 3b, 4). This amount of increase in FAME productivity is due to the improved growth trait as well as lipid accumulation even under $\mathrm{N}$ starvation conditions.

The analysis of the carbohydrate, protein, and chlorophyll contents likewise showed differences between the CC-124L and CC-124H. Under normal media, CC-124H had a nearly two fold higher carbohydrate content compared to the CC-124L, while the overall lipid contents were similar (Figs. 3a, 5a). This indicates that CC- $124 \mathrm{H}$ assimilates carbon into carbohydrates more aggressively than that of the CC-124L, either through photosynthesis or through greater assimilation of acetate. Under $\mathrm{S}$ starvation conditions, mutant cells also showed higher levels of carbohydrate accumulation than that of the CC-124L. Accumulation of higher levels of starch granules have been reported in C. reinhardtii subjected to $\mathrm{S}$ depleted growth conditions $[13,14]$. However, under $\mathrm{N}$ starvation conditions, CC- $124 \mathrm{H}$ was shown to accumulate lipids to a much greater extent than that of the CC$124 \mathrm{~L}$, while its overall carbohydrate contents decreased. One possible explanation is that under stress conditions, carbohydrate synthesis is downregulated in favor of lipid synthesis in mutants $[58,59]$. Another possibility is that the conversion and repartitioning of existing intracellular carbohydrates into fatty acid storage form may have a substantial contribution towards the observed increase in lipid contents [59, 60]. In addition, lower levels of protein content were found in CC- $124 \mathrm{H}$ compared to the CC$124 \mathrm{~L}$ under $\mathrm{S}$ depleted conditions. The lower percentage of proteins in the mutant cells can be directly attributed to the altered carbon partitioning and increased percentage of carbohydrates and lipids in the cells due to the fact that $\mathrm{CC}-124 \mathrm{H}$ has an elevated level of carbon fixation. Moreover, as mentioned previously, depletion of $\mathrm{N}$ and $\mathrm{S}$ in growth media has a profound effect on the metabolic pathways of microalgae. As expected, depletion of $\mathrm{N}$ in the media resulted in a substantial decrease in the overall protein content in both CC-124L and CC-124H. Reduction in the protein content is expected under $\mathrm{N}$ starvation due to the requirement of nitrogen in the synthesis of most amino acids, and as such cells typically enter cell cycle arrest while expressing higher levels of stress marker metabolites such as carbohydrates and lipids [13, 51].

Based upon all these observations, we assumed that CC-124H was modified through adaptive evolution during the maintenance of $\mathrm{CC}-124$ under laboratory conditions. To further understand the enhanced traits of CC- $124 \mathrm{H}$ in biomass and lipid production, we next performed SNPs/indels analysis which can identify non-synonymous substitutions at a molecular level. Our results revealed that many of the non-synonymous substitutions caused by SNPs/indels were found in genes required for cell cycle, division or proliferation. These included the ThiF family protein (Cre03.g165215), U-box and RING/ U-box proteins (Cre06.g252100 and Cre09.g399439), ubiquitin-specific protease 16 (UBP16, Cre06.g262500), leucine-rich repeat receptor protein kinase (LRR-RPK, Cre06.g297082), DEAD/DEAH box RNA helicase family protein (Cre03.g208833), dual specificity protein phosphatase (Creg06.g267250) and ankyrin repeat family protein (Cre06.g286950) (Table 3).

Thiamin, known as vitamin B1, is an essential cofactor that is synthesized in microalgae as well as plants and bacteria. ThiF motifs located in ubiquitin-activating enzyme (E1) form a thiol-ester bond with ubiquitin to facilitate ubiquitination, which signals for proteasomemediated degradation of a target protein [61]. Among the components of the ubiquitination systems, ubiquitin-ligase (E3) interacts with specific proteins. Higher plants are known to primarily possess three types of E3 ligase, which are RING, HECT, and U-box. Recent studies on ubiquitin systems in $C$. reinhardtii have involved various ubiquitin-mediated processes such as control of the circadian clock, disassembly of cilia and flagella, and lipid modulation [62, 63]. In this study, SNPs and indels were detected in the/U-box and RING/U-box proteins (Cre06.g252100 and Cre09.g399439), and it is predicted that mutations at these sites may be the cause behind the immobility and unique cell division characteristics of $\mathrm{CC}-124 \mathrm{H}$. Moreover, ubiquitin-specific protease 16 (UBP16, Cre06.g262500), annotated as AT4G24560 in A. thaliana, was found in this study. UBP16 exhibits partial redundancy and is stabilized under salt stress conditions, and it is also known to be involved in cell proliferation $[64,65]$.

In addition, SNPs were detected at the multi-functional gene, leucine-rich repeat receptor protein kinase (LRRRPK, Cre06.g297082). Leucine-rich repeat (LRR) motifs are conserved across many organisms and are known to interact with various proteins. The mutations in the LRR motifs may cause some phenotypic changes, especially in the reproductive cells [66]. In A. thaliana, a male EMS1 mutant encoding LRR-RPK had no cytokinesis of microspores [67].

The DEAD/DEAH box RNA helicase family protein (Cre03.g208833) is also proposed to be involved in cellular growth and division and has an important role in unwinding nucleic acids. In the case of Prorocentrum donghaiense, proteomics analysis shows that the DEAD/ DEAH box protein was upregulated during proliferation [68]. Dual specificity protein phosphatases (DUSP) are responsible for the dephosphorylation of serine, threonine and tyrosine and are also involved in MAP kinase signaling cascade. They can also be involved in the cell 
cycle, as downregulation of DUSP are linked to tumor proliferation in mammals $[69,70]$. Lastly, the ankyrin repeat family protein (Cre06.g286950) regulates many intracellular processes such as signal transduction and cell cycles [71]. The SNPs in the cell cycle related genes are thought to have resulted in substantial morphological changes in CC-124H. Indeed, CC-124H showed increased proportion of the cells in the palmella stage of development, and lacked flagella which resulted in general loss of mobility compared to the wild-type cells.

While CC-124H accumulated much higher lipid contents than CC-124L, surprisingly, there were no SNPs in the coding region of the genes directly involved in the lipid synthesis. One possibility is that the mutations in the cell cycle machinery of the organism have indirectly led to the changes in the lipid accumulation. The above mentioned palmelloid phenotype in $\mathrm{CC}-124 \mathrm{H}$ is thought to have originated due to the irregular cell cycle. A previous study has found that cells with unregulated cell division such as tumor cells often show high lipid contents [72-74]. In addition, it should be noted that there were hundreds of SNPs that occurred in the non-coding regions of the genome such as promoter, terminator, and introns. Most of these could not be identified and were not included in the results of this study. While the SNPs in the coding region often results in loss of function mutations which is deleterious to the survival of the organism, SNPs in the non-coding regions do not cause such loss of function mutations, which allows the organism to retain and accumulate these in far greater numbers. However, the SNPs in the non-coding regions can result in substantial changes in the expression level of the individual genes, and multiple changes such as these can have global effects on the overall systems biology of the organism. In addition, it is quite probable that there were SNP's in the UTR of lipid synthesis related genes such as diacylglycerol acyltransferase, plastid-lipid associated protein PAP, and pyruvate dehydrogenase kinase which directly resulted in the expression level of these genes. It is thought that all of these changes could have resulted in substantial alterations in the overall lipid synthesis in the organism.

Since the initial study by Goto et al., many studies have revealed that photoperiodic cell division is mediated by the circadian clock, and mRNA abundances are oscillated during the circadian cycle in the unicellular photosynthetic algae, Chlamydomonas and Ostreococcus [75-78]. More recently, additional research has reported that the C. reinhardtii strain CC-503 evolved for 1880 generations under a continuous light condition had 149 SNPs resulting in non-synonymous amino acid substitutions with a $35 \%$ greater growth rate compared to its progenitor population [26]. These results indicate that several physiological events in $\mathrm{CC}-124 \mathrm{H}$ including cell proliferation timing and frequency are possibly adapted to gain selective advantages under a continuous illumination condition, although the underlying mechanism remains undiscovered in this study.

\section{Conclusion}

In the present study, we isolated the C. reinhardtii CC$124 \mathrm{H}$ strain whose growth trait was distinct from its ancestral WT, and further demonstrated that CC-124H exhibited significantly increased amount of biomass and lipid production compared to the CC-124L. Moreover, an integrated genome wide analysis allowed us to identify sequence variations within individual genomes which may result in the phenotypic changes of CC- $124 \mathrm{H}$. These findings suggest that the concept of adaptive evolution combined with genome wide analysis can be used as an alternative strategy for the development of microalgal strains that meet academic and industrial standards for biofuel production.

\section{Methods \\ Microalgal strain, culture conditions and isolation of CC-124H}

Chlamydomonas reinhardtii CC-124(-) strain was purchased from the Chlamydomonas Resource Center at the University of Minnesota (St. Paul, MN, USA; http:// chlamycollection.org/). Cells were maintained on Trisacetate-phosphate (TAP) agar medium [79] consisting of $2.42 \mathrm{~g} / \mathrm{L}$ Tris, $0.375 \mathrm{~g} / \mathrm{L} \mathrm{NH}_{4} \mathrm{Cl}, 0.1 \mathrm{~g} / \mathrm{L} \mathrm{MgSO}{ }_{4} \cdot 7 \mathrm{H}_{2} \mathrm{O}$, $0.05 \mathrm{~g} / \mathrm{L} \mathrm{CaCl}{ }_{2} \cdot 2 \mathrm{H}_{2} \mathrm{O}, 0.0108 \mathrm{~g} / \mathrm{L} \mathrm{K}_{2} \mathrm{HPO}_{4}, 0.0054 \mathrm{~g} / \mathrm{L}$ $\mathrm{KH}_{2} \mathrm{PO}_{4}, 1 \mathrm{~mL} / \mathrm{L}$ glacial acetic acid and $1 \mathrm{~mL} / \mathrm{L}$ Hutner's trace elements $\left(50 \mathrm{~g} / \mathrm{L} \mathrm{Na}{ }_{2}\right.$ EDTA $2 \mathrm{H}_{2} \mathrm{O}, 22 \mathrm{~g} / \mathrm{L}$ $\mathrm{ZnSO}_{4} \cdot 7 \mathrm{H}_{2} \mathrm{O}, 11.4 \mathrm{~g} / \mathrm{L} \mathrm{H}_{3} \mathrm{BO}_{3}, 5.06 \mathrm{~g} / \mathrm{L} \mathrm{MnCl}_{2} \cdot 4 \mathrm{H}_{2} \mathrm{O}$, $1.61 \mathrm{~g} / \mathrm{L} \mathrm{CoCl}{ }_{2} \cdot 6 \mathrm{H}_{2} \mathrm{O}, 1.57 \mathrm{~g} / \mathrm{L} \mathrm{CuSO} 4.5 \mathrm{H}_{2} \mathrm{O}, 1.10 \mathrm{~g} / \mathrm{L}$ $\left(\mathrm{NH}_{4}\right)_{6} \mathrm{Mo}_{7} \mathrm{O}_{24} \cdot 7 \mathrm{H}_{2} \mathrm{O}$, and $4.99 \mathrm{~g} / \mathrm{L} \mathrm{FeSO}_{4} \cdot 7 \mathrm{H}_{2} \mathrm{O}$ at $25^{\circ} \mathrm{C}$ under continuous illumination of $50 \mu \mathrm{mol} / \mathrm{m}^{2} / \mathrm{s}$. Cells were transferred onto fresh TAP agar plate once every month for 5 years. During the maintenance of C. reinhardtii CC-124(-), a cell representing rapid growth, $\mathrm{CC}-124 \mathrm{H}$, was isolated. Both the microalgal strains, $C$. reinhardtii $\mathrm{CC}-124(-)$ and $\mathrm{CC}-124 \mathrm{H}$ were cultivated in $500 \mathrm{~mL}$ volumetric flasks with $200 \mathrm{~mL}$ working volumes at $25{ }^{\circ} \mathrm{C}$ with shaking $(120 \mathrm{rpm})$ under fluorescent light $\left(120 \mu \mathrm{mol} / \mu \mathrm{mol} / \mathrm{m}^{2} / \mathrm{s}\right)$.

\section{Growth and nutrient analysis}

CC-124L and CC-124H strains were cultivated under normal conditions (TAP medium) as described above: $25{ }^{\circ} \mathrm{C}, 120 \mathrm{rpm}$ and $120 \mu \mathrm{mol} / \mathrm{m}^{2} / \mathrm{s}$ fluorescent light. For the $\mathrm{N}$ and $\mathrm{S}$ starvation, stationary phase cells were harvested and washed twice with TAP medium, and then, the cells $\left(\mathrm{OD}_{750}: \sim 0.7\right)$ were inoculated into TAP 
medium without $\mathrm{N}$ and $\mathrm{S}$, respectively. Cell growth was determined by measuring the cell density (in cells $/ \mathrm{mL}$ ), optical density (OD) and dry cell weight (DCW). Cell density was counted with a cell counter (Cellometer AutoT4 $^{\mathrm{TM}}$, Nexcelom Bioscience, USA), and the $\mathrm{OD}_{750}$ was measured by a UV/Vis spectrometer (Shimadzu Co., Japan) at the indicated time points, and the DCW was estimated by filtering the cells with GF/C filter paper (Whatman, USA), drying at $120^{\circ} \mathrm{C}$ overnight, and weighing on a microbalance (CP224S, Sartorious, Germany). The specific growth rate of the microalgae based on the DCW was calculated with the following equation:

Specific growth rate $(\mu / \mathrm{h})=\ln \left(X_{2} / X_{1}\right) /\left(t_{2}-t_{1}\right)$, where $X_{1}$ and $X_{2}$ are the initial and final DCW, and $T_{1}$ and $T_{2}$ are the initial and final times.

The concentrations of ammonium $\left(\mathrm{NH}_{4}{ }^{+}\right)$, (phosphate $\left(\mathrm{PO}_{4}{ }^{3-}\right)$, sulfate $\left(\mathrm{SO}_{4}{ }^{2-}\right)$ and acetate $\left(\mathrm{CH}_{3} \mathrm{CO}_{2}{ }^{-}\right)$in the broth were determined by ion chromatography (881 compact IC pro, Metrohm, Swiss) with a Metrosep C4 150 column, Metrosep A Supp5 150 column and Metrosep Organic Acids 250 column for cations, anions and organic acids, respectively.

\section{Fatty acid methyl esters (FAMEs) analysis by gas chromatography (GC)}

Microalgal cells were harvested by centrifugation at $5035 \times g$ for $10 \mathrm{~min}$. (Supra-22K, Hanil Science Industrial, Republic of Korea). The pellets were washed twice with deionized water, lyophilized at $-80{ }^{\circ} \mathrm{C}$ for 3 days and then used for lipid extraction. For the lipid extraction, a chloroform-methanol mixture $(2: 1, \mathrm{v} / \mathrm{v})$ was added to $10 \mathrm{mg}$ of lyophilized cells and then vigorously mixed in a Teflon-sealed screw-capped Pyrex tube (Pyrex, USA) for $10 \mathrm{~min} .0 .5 \mathrm{mg}$ of heptadecanoic acid (C17:0) were added as an internal standard for gas chromatography (GC). For transesterification which converts extracted lipid into fatty acid methyl esters (FAMEs), $1 \mathrm{~mL}$ of methanol and $300 \mu \mathrm{L}$ of sulfuric acid were added and then incubated at $100{ }^{\circ} \mathrm{C}$ for $20 \mathrm{~min}$. After cooling down, $0.3 \mathrm{~N}$ concentration of sodium hydroxide was added to rinse the remaining methanol and sulfuric acid. After centrifugation at $4000 \mathrm{rpm}$ for $10 \mathrm{~min}$ at room temperature, the organic phase (lower layer) was filtered using a $20 \mu \mathrm{m}$ RC-membrane syringe filter (Sartorius Stedim Biotech, Germany). FAMEs were analyzed by GC (HP5890, Agilent, USA) equipped with a flame ionized detector (FID) and an HP-INNOWAX polyethylene glycol column $(30 \mathrm{~m} \times 0.32 \mathrm{~mm} \times 0.5 \mu \mathrm{m} ; \mathrm{H} 19091 \mathrm{~N}-213$, Agilent, USA). The FAME composition and content were determined with a 37-component mix of FAME standards (F.A.M.E. Mix C8-C24, Supelco, USA).

\section{Biochemical component analysis: total carbohydrates and proteins}

To determine the biochemical components, $5 \mathrm{mg}$ of a lyophilized biomass were required. Samples were reacted with anthrone reagents in a sulfuric acid/deionized water mixture $(3: 1, \mathrm{v} / \mathrm{v})$ at $100{ }^{\circ} \mathrm{C}$ for $15 \mathrm{~min}$. After cooling on ice, the absorbance was measured at $620 \mathrm{~nm}$ and calibrated with glucose at concentration of $0-240 \mathrm{mg} / \mathrm{L}$ as a standard [80]. To measure the protein content, the Quick Start ${ }^{\mathrm{TM}}$ Bradford Protein Assay (Biorad, USA) was used. The biomass was reacted with $1 \mathrm{~N}$ sodium hydroxide solution at $100{ }^{\circ} \mathrm{C}$ for $10 \mathrm{~min}$. Then, the disrupted cells were reacted with $1 \times$ dye reagent for $5 \mathrm{~min}$., and then, the absorbance was measured at $595 \mathrm{~nm}$ and calibrated with BSA standards.

\section{Chlorophyll fluorescence}

Chlorophyll contents of $C$. reinhardtii were measured with methanol extraction using the following protocol [81]. $5 \mathrm{~mL}$ cultures of cells were harvested at $5035 \times g$ for $10 \mathrm{~min}$ and washed twice with deionized water. The pellets were resuspended in a same volume of methanol and incubated in a dark condition at $4{ }^{\circ} \mathrm{C}$ for $1 \mathrm{~h}$. After centrifugation at $5035 \times g$ for $10 \mathrm{~min}$, the absorbance of the supernatant was measured at 652 and $665 \mathrm{~nm}$. The concentrations of chlorophyll $\mathrm{a}$ and $\mathrm{b}$ were calculated using the following equations.

$$
\begin{aligned}
\text { Chl a }(\mu \mathrm{g} / \mathrm{mL})= & -8.0962 \times \mathrm{OD}_{652 \mathrm{~nm}} \\
& +16.5169 \times \mathrm{OD}_{665} \mathrm{~nm} \\
\text { Chl b }(\mu \mathrm{g} / \mathrm{mL})= & 27.4405 \times \mathrm{OD}_{652 \mathrm{~nm}} \\
& -12.1688 \times \mathrm{OD}_{665 \mathrm{~nm}}
\end{aligned}
$$

Lastly, the chlorophyll concentration was normalized with the cell density using Cellometer AutoT4 (Nexcelom Bioscience, USA).

\section{Transmission electron microscopy (TEM)}

Cells were centrifuged at $1644 \times g$ for $5 \mathrm{~min}$ and washed twice with $0.1 \mathrm{M}$ phosphate buffer. Then, $0.1 \mathrm{M}$ phosphate buffer containing $2.5 \%$ glutaraldehyde was used for fixation of each strain. After treatment with the Epon 812 embedding medium, specimens were observed under a bio-Transmission electron microscopy (Tecnai G2 Spirit, FEI Co., Netherlands, Installed at Korea Basic Science Institute).

\section{BODIPY staining and confocal microscopy}

For detection of lipid bodies, cells were stained by BODIPY $^{\circledR}$ 505/515 (1 $\mu \mathrm{M}, 4,4$-difluoro-1,3,5,7-tetramethyl-4-bora-3a,4a-diaza-s-indacene, Invitrogen, USA) solubilized in $0.2 \%$ dimethyl sulfoxide (DMSO) and 
incubated under a dark condition for $10 \mathrm{~min}$. BODIPY stained cells were observed using a laser scanning confocal microscope (LSM 510 META NLO, Carl Zeiss, Germany) with the appropriate excitation and emission laser units (Argon $488 \mathrm{~nm} ; 30 \mathrm{~mW}$ for excitation and $\mathrm{HeNe}$ $543 \mathrm{~nm} ; 1 \mathrm{~mW}$ for emission). Images were taken with a $50 \times$ magnification, and image processing was done with the LSM Image Browser (Carl Zeiss, Germany).

\section{Genomic DNA preparation for DNA sequencing}

Genomic DNA was extracted by a modified version of the standard phenol/chloroform extraction method [82]. Briefly, $5 \mathrm{~mL}$ of exponentially growing C. reinhardtii cells in TAP medium were harvested for genomic DNA extraction. Pellets were washed with $50 \mathrm{mM}$ EDTA until no clumps were visible. After centrifugation at $7000 \mathrm{rpm}$ for $10 \mathrm{~min}, 150 \mu \mathrm{L}$ of distilled water and $300 \mu \mathrm{L}$ of SDSEB were added to the pellets. Subsequently, both $250 \mu \mathrm{L}$ of phenol and chloroform were added and vortexed for $5 \mathrm{~min}$. After centrifugation, the supernatants were separated, and the previous steps were repeated with the treatment of phenol and chloroform. For DNA precipitation, 2 volumes of pure ethanol were added and then kept at $-20{ }^{\circ} \mathrm{C}$ for $20 \mathrm{~min}$ and then centrifuged. Finally, DNA pellets were solubilized with an appropriate volume of TE buffer ( $1 \mathrm{mM}$ Tris- $\mathrm{HCl}$ and $0.2 \mathrm{mM}$ EDTA, both of $\mathrm{pH} 8$ ).

\section{Whole genome sequencing and SNPs/indels analysis}

A schematic workflow for the genome sequencing and SNPs/indels analysis was presented in Additional file 3: Figure S2. Briefly, DNA libraries and cluster construction were performed using TruSeq DNA PCR free sample Preparation Kit (Illumina, USA), TruSeq Rapid SBS kit (Illumina, USA) and TruSeq Rapid PE Cluster kit (Illumina, USA). The $C$. reinhardtii DNA libraries were sequenced using Illumina HiSeq 2500 (Illumina, USA). The sequencing data were submitted to the NCBI Sequence Read Archive (SRA) under accession code SRP113748. A paired-end sequencing platform was used to analyze the SNPs/indels between CC-124H and CC124L by Illumina HiSeq 2500. Short read sequences from CC-124 and CC-124H were trimmed by the SolexaQA package with the sequence quality and length trimming standard (Probability value: 0.05 , phred quality score: 20 , and minimum read length: $25 \mathrm{bp}$ ). Then, each sequencing dataset was mapped to the $C$. reinhardtii reference genome v5.5 (Phytozome ver 10.1; http://www.phytozome.net/) using the Burrows-Wheeler Aligner (BWA). The raw SNPs/indels detection and extraction of consensus were done with SAMtools and In-house script. The detected SNPs/indels were filtrated with the following criteria: read depth: $\geq 3$; mapping quality: $\geq 30$ and biallelic SNPs/indels. Unmapping regions were eliminated in the case of unknown nucleotides. Finally, the SNPs/indels were classified and annotated by Pfam (http://pfam.sanger.ac.uk/), Panther (http://www.pantherdb.org), KOG (http://www.ncbi.nlm.nih.gov/COG/), KEEG (http://www.genome.jp/kegg/), and GO (http:// www.geneontology.org/) analysis.

\section{Additional files}

Additional file 1: Table S1. Specific growth rate of CC-124 in year 2010, 2013, and 2015

Additional file 2: Figure S1. Cell size distribution of CC-124L and CC$124 \mathrm{H}$ in liquid TAP medium.

Additional file 3: Figure S2. Flow chart of the genome wide SNPS/ indels analysis method.

Additional file 4. List of genome data of single nucleotide polymorphisms (SNPs) and insertion-deletions (indels) comparison of CC-124L and CC-124H.

\section{Abbreviations}

WT: wild-type; N: nitrogen; S: sulfur; TAG: triacylglycerol; OD: optical density; FAME: fatty acid methyl ester; SNPs: single nucleotide polymorphisms; indels: insertion/deletions; GMO: genetically modified organism; NGS: next-generation sequencing; TEM: transmission electron microscope; DCW: dry cell weight; TAP: Tris-acetate-phosphate.

\section{Authors' contributions}

SES and HGK isolated CC-124H strain and conducted cultivation during the previous 5 years. BL and SES designed the whole scheme of the experiments and conducted the experiments. HGK, WS, NKK and BrJ helped to analyze and interpret the experimental data. SES, BL and YKC wrote manuscript. All authors read and approved the final manuscript.

\section{Author details}

${ }^{1}$ Department of Chemical and Biomolecular Engineering, KAIST, 291 Daehak-ro, Yuseong-gu, Daejeon 34141, Republic of Korea. ${ }^{2}$ Advanced Biomass R\&D Center, 291 Daehak-ro, Yuseong-gu, Daejeon 34141, Republic of Korea. ${ }^{3}$ Present Address: LG Chem, 188 Munji-ro, Yuseong-gu, Daejeon 34122, Republic of Korea.

\section{Acknowledgements}

We would like to honor and acknowledge the late Professor Ji-Won Yang for his inspiration on this project and the establishment of the Advanced Biomass $R \& D$ Center (ABC). This work was supported by the Advanced Biomass R\&D Center (ABC) of Global Frontier Project funded by the Ministry of Science and ICT (ABC-2010-0029728 and 2011-0031350).

\section{Competing interests}

The authors declare that they have no competing interests.

Availability of supporting data

Supporting data are provided in Additional files 1, 2, 3 and 4.

Ethics approval and consent to participate

Not applicable.

\section{Publisher's Note}

Springer Nature remains neutral with regard to jurisdictional claims in published maps and institutional affiliations.

Received: 29 August 2017 Accepted: 14 December 2017

Published online: 22 December 2017 


\section{References}

1. Ho SH, Ye X, Hasunuma T, Chang JS, Kondo A. Perspectives on engineering strategies for improving biofuel production from microalgae-a critical review. Biotechnol Adv. 2014;32:1448-59.

2. Wijffels RH, Barbosa MJ. An outlook on microalgal biofuels. Science. 2010;329:796-9.

3. Chisti Y. Biodiesel from microalgae. Biotechnol Adv. 2007:25:294-306.

4. Scaife MA, Nguyen GT, Rico J, Lambert D, Helliwell KE, Smith AG. Establishing Chlamydomonas reinhardtii as an industrial biotechnology host. Plant J. 2015;82:532-46.

5. Merchant SS, Kropat J, Liu B, Shaw J, Warakanont J. TAG, you're it! Chlamydomonas as a reference organism for understanding algal triacylglyc erol accumulation. Curr Opin Biotechnol. 2012;23:352-63.

6. Mussgnug JH. Genetic tools and techniques for Chlamydomonas reinhardtii. Appl Microbiol Biotechnol. 2015;99:5407-18.

7. Scranton MA, Ostrand JT, Fields FJ, Mayfield SP. Chlamydomonas as a model for biofuels and bio-products production. Plant J. 2015;82:523-31.

8. Chen CY, Yeh KL, Aisyah R, Lee DJ, Chang JS. Cultivation, photobioreactor design and harvesting of microalgae for biodiesel production: a critical review. Bioresour Technol. 2011;102:71-81.

9. Siaut M, Cuine S, Cagnon C, Fessler B, Nguyen M, Carrier P, et al. Oil accumulation in the model green alga Chlamydomonas reinhardtii: characterization, variability between common laboratory strains and relationship with starch reserves. BMC Biotechnol. 2011:11:7.

10. Wang ZT, Ullrich N, Joo S, Waffenschmidt S, Goodenough U. Algal lipid bodies: stress induction, purification, and biochemical characterization in wild-type and starchless Chlamydomonas reinhardtii. Eukaryot Cell. 2009;8:1856-68

11. Work VH, Radakovits R, Jinkerson RE, Meuser JE, Elliott LG, Vinyard DJ, et al. Increased lipid accumulation in the Chlamydomonas reinhardtii sta7-10 starchless isoamylase mutant and increased carbohydrate synthesis in complemented strains. Eukaryot Cell. 2010;9:1251-61.

12. Li Y, Han D, Hu G, Dauvillee D, Sommerfeld M, Ball S, et al. Chlamydomonas starchless mutant defective in ADP-glucose pyrophosphorylase hyper-accumulates triacylglycerol. Metab Eng. 2010;12:387-91.

13. Cakmak T, Angun P, Demiray YE, Ozkan AD, Elibol Z, Tekinay T. Differential effects of nitrogen and sulfur deprivation on growth and biodiesel feedstock production of Chlamydomonas reinhardtii. Biotechnol Bioeng. 2012;109:1947-57.

14. Sato A, Matsumura R, Hoshino N, Tsuzuki M, Sato N. Responsibility of regulatory gene expression and repressed protein synthesis for triacylglycerol accumulation on sulfur-starvation in Chlamydomonas reinhardtii. Front Plant Sci. 2014;5:444.

15. Polle JE, Kanakagiri SD, Melis A. tla1, a DNA insertional transformant of the green alga Chlamydomonas reinhardtii with a truncated light-harvesting chlorophyll antenna size. Planta. 2003;217:49-59.

16. Kirst $\mathrm{H}$, Melis A. The chloroplast signal recognition particle (CpSRP) pathway as a tool to minimize chlorophyll antenna size and maximize photosynthetic productivity. Biotechnol Adv. 2014;32:66-72.

17. Polle JEW, Kanakagiri S, Jin E, Masuda T, Melis A. Truncated chlorophyll antenna size of the photosystems - a practical method to improve microalgal productivity and hydrogen production in mass culture. Int J Hydrog Energy. 2002;27:1257-64.

18. Kirst H, Garcia-Cerdan JG, Zurbriggen A, Melis A. Assembly of the light-harvesting chlorophyll antenna in the green alga Chlamydomonas reinhardtii requires expression of the TLA2-CPFTSY gene. Plant Physiol. 2012;158:930-45

19. Kirst H, Garcia-Cerdan JG, Zurbriggen A, Ruehle T, Melis A. Truncated photosystem chlorophyll antenna size in the green microalga Chlamydomonas reinhardtii upon deletion of the TLA3-CPSRP43 gene. Plant Physiol. 2012;160:2251-60

20. La Russa M, Bogen C, Uhmeyer A, Doebbe A, Filippone E, Kruse O, et al. Functional analysis of three type-2 DGAT homologue genes for triacylglycerol production in the green microalga Chlamydomonas reinhardtii. J Biotechnol. 2012;162:13-20.

21. Deng XD, Gu B, LiYJ, Hu XW, Guo JC, Fei XW. The roles of acyl-CoA: diacylglycerol acyltransferase 2 genes in the biosynthesis of triacylglycerols by the green algae Chlamydomonas reinhardtii. Mol Plant. 2012;5:945-7.

22. Hawkins RL, Nakamura M. Expression of human growth hormone by the eukaryotic alga, Chlorella. Curr Microbiol. 1999:38:335-41.
23. Cerutti H, Johnson AM, Gillham NW, Boynton JE. Epigenetic silencing of a foreign gene in nuclear transformants of Chlamydomonas. Plant Cell. 1997:9:925-45.

24. Iglesias VA, Moscone EA, Papp I, Neuhuber F, Michalowski S, Phelan T, et al. Molecular and cytogenetic analyses of stably and unstably expressed transgene loci in tobacco. Plant Cell. 1997;9:1251-64.

25. Fuhrmann M, Oertel W, Hegemann P. A synthetic gene coding for the green fluorescent protein (GFP) is a versatile reporter in Chlamydomonas reinhardtii. Plant J. 1999;19:353-61.

26. Perrineau MM, Gross J, Zelzion E, Price DC, Levitan O, Boyd J, et al. Using natural selection to explore the adaptive potential of Chlamydomonas reinhardtii. PLoS ONE. 2014;9:e92533.

27. Collins S, Bell G. Phenotypic consequences of 1,000 generations of selection at elevated $\mathrm{CO}_{2}$ in a green alga. Nature. 2004;431:566-9.

28. Forster B, Osmond CB, Pogson BJ. Improved survival of very high light and oxidative stress is conferred by spontaneous gain-of-function mutations in Chlamydomonas. Biochim Biophys Acta. 2005;1709:45-57.

29. Bell G. Experimental evolution of heterotrophy in a green alga. Evolution. 2013;67:468-76.

30. Nowrousian M. Next-generation sequencing techniques for eukaryotic microorganisms: sequencing-based solutions to biological problems. Eukaryot Cell. 2010;9:1300-10.

31. Schierenbeck L, Ries D, Rogge K, Grewe S, Weisshaar B, Kruse O. Fast forward genetics to identify mutations causing a high light tolerant phenotype in Chlamydomonas reinhardtii by whole-genome-sequencing BMC Genom. 2015;16:57

32. Jang $\mathrm{H}$, Ehrenreich IM. Genome-wide characterization of genetic variation in the unicellular, green alga Chlamydomonas reinhardtii. PLOS ONE. 2012;7:e41307.

33. Lin H, Miller ML, Granas DM, Dutcher SK. Whole genome sequencing identifies a deletion in protein phosphatase 2A that affects its stability and localization in Chlamydomonas reinhardtii. PLoS Genet. 2013:9:e1003841.

34. Dutcher SK, Li L, Lin H, Meyer L, Giddings TH Jr, Kwan AL, et al. Wholegenome sequencing to identify mutants and polymorphisms in Chlamydomonas reinhardtii. G3 (Bethesda). 2012;2:15-22.

35. James GO, Hocart $\mathrm{CH}$, Hillier W, Chen H, Kordbacheh F, Price GD, et al. Fatty acid profiling of Chlamydomonas reinhardtii under nitrogen deprivation. Bioresour Technol. 2011;102:3343-51.

36. Converti A, Casazza AA, Ortiz EY, Perego P, Del Borghi M. Effect of temperature and nitrogen concentration on the growth and lipid content of Nannochloropsis oculata and Chlorella vulgaris for biodiesel production. Chem Eng Process. 2009;48:1146-51.

37. Volkman JK, Brown MR, Dunstan GA, Jeffrey SW. The biochemical-composition of marine microalgae from the class Eustigmatophyceae. J Phycol. 1993;29:69-78

38. Subramanian A, Tamayo P, Mootha VK, Mukherjee S, Ebert BL, Gillette MA, et al. Gene set enrichment analysis: a knowledge-based approach for interpreting genome-wide expression profiles. Proc Natl Acad Sci USA. 2005;102:15545-50.

39. Radakovits R, Jinkerson RE, Darzins A, Posewitz MC. Genetic engineering of algae for enhanced biofuel production. Eukaryot Cell. 2010;9:486-501.

40. Schoepp NG, Stewart RL, Sun V, Quigley AJ, Mendola D, Mayfield SP, et al. System and method for research-scale outdoor production of microalgae and cyanobacteria. Bioresour Technol. 2014;166:273-81.

41. Griffiths MJ, Harrison STL. Lipid productivity as a key characteristic for choosing algal species for biodiesel production. J Appl Phycol. 2009;21:493-507.

42. Snow AA, Smith VH. Genetically engineered algae for biofuels: a key role for ecologists. Bioscience. 2012;62:765-8.

43. Snow AA, Andow DA, Gepts P, Hallerman EM, Power A, Tiedje JM, et al. Genetically engineered organisms and the environment: current status and recommendations. Ecol Appl. 2005;15:377-404.

44. Wolt JD, Keese P, Raybould A, Fitzpatrick JW, Burachik M, Gray A, et al. Problem formulation in the environmental risk assessment for genetically modified plants. Transgenic Res. 2010;19:425-36.

45. Anandarajah K, Mahendraperumal G, Sommerfeld M, Hu Q. Characterization of microalga Nannochloropsis sp. mutants for improved production of biofuels. Appl Energ. 2012;96:371-7. 
46. Elena SF, Lenski RE. Evolution experiments with microorganisms: the dynamics and genetic bases of adaptation. Nat Rev Genet. 2003:4:457-69.

47. Blount ZD, Barrick JE, Davidson CJ, Lenski RE. Genomic analysis of a key innovation in an experimental Escherichia coli population. Nature. 2012;489:513-8

48. Kawecki TJ, Lenski RE, Ebert D, Hollis B, Olivieri I, Whitlock MC. Experimental evolution. Trends Ecol Evol. 2012;27:547-60.

49. Nakanishi A, Aikawa S, Ho SH, Chen CY, Chang JS, Hasunuma T, et al. Development of lipid productivities under different $\mathrm{CO}_{2}$ conditions of marine microalgae Chlamydomonas sp. JSC4. Bioresour Technol. 2014; 152:247-52

50. Miller R, Wu GX, Deshpande RR, Vieler A, Gartner K, Li XB, et al. Changes in transcript abundance in Chlamydomonas reinhardtii following nitrogen deprivation predict diversion of metabolism. Plant Physiol. 2010;154:1737-52.

51. Park JJ, Wang HX, Gargouri M, Deshpande RR, Skepper JN, Holguin FO, et al. The response of Chlamydomonas reinhardtii to nitrogen deprivation: a systems biology analysis. Plant J. 2015;81:611-24.

52. Lv HX, Qu G, Qi XZ, Lu LN, Tian CG, Ma YH. Transcriptome analysis of Chlamydomonas reinhardtii during the process of lipid accumulation. Genomics. 2013;101:229-37.

53. Corteggiani Carpinelli E, Telatin A, Vitulo N, Forcato C, D'Angelo M, Schiavon R, et al. Chromosome scale genome assembly and transcriptome profiling of Nannochloropsis gaditana in nitrogen depletion. Mol Plant. 2014;7:323-35

54. Li J, Han D, Wang D, Ning K, Jia J, Wei L, et al. Choreography of transcriptomes and lipidomes of nannochloropsis reveals the mechanisms of oil synthesis in microalgae. Plant Cell. 2014;26:1645-65.

55. Msanne J, Xu D, Konda AR, Casas-Mollano JA, Awada T, Cahoon EB, et al. Metabolic and gene expression changes triggered by nitrogen deprivation in the photoautotrophically grown microalgae Chlamydomonas reinhardtii and Coccomyxa sp. C-169. Phytochemistry. 2012;75:50-9.

56. Rodolfi L, Zittelli GC, Bassi N, Padovani G, Biondi N, Bonini G, et al. Microalgae for oil: strain selection, induction of lipid synthesis and outdoor mass cultivation in a low-cost photobioreactor. Biotechnol Bioeng. 2009;102:100-12

57. Hu Q, Sommerfeld M, Jarvis E, Ghirardi M, Posewitz M, Seibert M, et al. Microalgal triacylglycerols as feedstocks for biofuel production: perspectives and advances. Plant J. 2008;54:621-39.

58. Zhu BH, Shi HP, Yang GP, Lv NN, Yang M, Pan KH. Silencing UDP-glucose pyrophosphorylase gene in Phaeodactylum tricornutum affects carbon allocation. New Biotechnol. 2016;33:237-44.

59. Johnson X, Alric J. Central carbon metabolism and electron transport in Chlamydomonas reinhardtii: metabolic constraints for carbon partitioning between oil and starch. Eukaryot Cell. 2013;12:776-93.

60. Li YT, Han DX, Sommerfeld M, Hu QA. Photosynthetic carbon partitioning and lipid production in the oleaginous microalga Pseudochlorococcum sp. (Chlorophyceae) under nitrogen-limited conditions. Bioresour Technol. 2011;102:123-9.

61. Hatakeyama S, Nakayama KI. U-box proteins as a new family of ubiquitin ligases. Biochem Biophys Res Commun. 2003;302:635-45.

62. Huang KY, Diener DR, Rosenbaum JL. The ubiquitin conjugation system is involved in the disassembly of cilia and flagella. J Cell Biol. 2009:186:601-13.

63. Luo QL, Li YJ, Wang WQ, Fei XW, Deng XD. Genome-wide survey and expression analysis of Chlamydomonas reinhardtii U-box E3 ubiquitin ligases (CrPUBs) reveal a functional lipid metabolism module. Plos ONE. 2015;10(3):e0122600.

64. Liu YF, Wang F, Zhang HY, He H, Ma LG, Deng XW. Functional characterization of the Arabidopsis ubiquitin-specific protease gene family reveals specific role and redundancy of individual members in development. Plant J. 2008;55:844-56.
65. Zhou HP, Zhao JF, Yang YQ, Chen CX, Liu YF, Jin XH, et al. UBIQUITIN-SPECIFIC PROTEASE16 modulates salt tolerance in Arabidopsis by Regulating $\mathrm{Na}^{+} / \mathrm{H}^{+}$antiport activity and serine hydroxymethyltransferase stability. Plant Cell. 2012;24:5106-22.

66. Dievart A, Clark SE. Using mutant alleles to determine the structure and function of leucine-rich repeat receptor-like kinases. Curr Opin Plant Biol. 2003:6:507-16.

67. Zhao DZ, Wang GF, Speal B, Ma H. The EXCESS MICROSPOROCYTES1 gene encodes a putative leucine-rich repeat receptor protein kinase that controls somatic and reproductive cell fates in the Arabidopsis anther. Gene Dev. 2002;16:2021-31.

68. Wang DZ, Zhang YJ, Zhang SF, Lin L, Hong HS. Quantitative proteomic analysis of cell cycle of the dinoflagellate Prorocentrum donghaiense (Dinophyceae). Plos ONE. 2013;8(5):e63659.

69. Shen J, Zhou S, Shi L, Liu X, Lin H, Yu H, et al. DUSP1 inhibits cell proliferation, metastasis and invasion and angiogenesis in gallbladder cancer. Oncotarget. 2017:8:12133-44.

70. Lopes LJS, Tesser-Gamba F, Petrilli AS, de Seixas Alves MT, Garcia-Filho RJ, Toledo SRC. MAPK pathways regulation by DUSP1 in the development of osteosarcoma: potential markers and therapeutic targets. Mol Carcinog. 2017;56:1630-41.

71. Voronin DA, Kiseleva EV. Functional role of proteins containing ankyrin repeats. Cell Tissue Biol. 2007;49:989-99.

72. Beloribi-Djefaflia S, Vasseur S, Guillaumond F. Lipid metabolic reprogramming in cancer cells. Oncogenesis. 2016;5:e189.

73. Accioly MT, Pacheco P, Maya-Monteiro CM, Carrossini N, Robbs BK, Oliveira SS, et al. Lipid bodies are reservoirs of cyclooxygenase-2 and sites of prostaglandin-E2 synthesis in colon cancer cells. Cancer Res. 2008;68:1732-40.

74. Qiu B, Ackerman D, Sanchez DJ, Li B, Ochocki JD, Grazioli A, et al. HIF2alpha-dependent lipid storage promotes endoplasmic reticulum homeostasis in clear-cell renal cell carcinoma. Cancer Discov. 2015;5:652-67.

75. Moulager M, Monnier A, Jesson B, Bouvet R, Mosser J, Schwartz C, et al. Light-dependent regulation of cell division in Ostreococcus: evidence for a major transcriptional input. Plant Physiol. 2007;144:1360-9.

76. Fujiwara S, Ishida N, Tsuzuki M. Circadian expression of the carbonic anhydrase gene, Cah1, in Chlamydomonas reinhardtii. Plant Mol Biol. 1996:32:745-9.

77. Hwang S, Kawazoe R, Herrin DL. Transcription of tufA and other chloroplast-encoded genes is controlled by a circadian clock in Chlamydomonas. Proc Natl Acad Sci USA. 1996;93:996-1000.

78. Goto K, Johnson CH. Is the cell-division cycle gated by a circadian clockthe case of Chlamydomonas-Reinhardtii. J Cell Biol. 1995;129:1061-9.

79. Harris EH. The Chlamydomonas sourcebook: a comprehensive guide to biology and laboratory use. San Diego: Academic Press; 1989.

80. Trevelyan WE, Forrest RS, Harrison JS. Determination of yeast carbohydrates with the anthrone reagent. Nature. 1952;170:626-7.

81. Ritchie RJ. Consistent sets of spectrophotometric chlorophyll equations for acetone, methanol and ethanol solvents. Photosynth Res. 2006;89:27-41.

82. Sambrook J, Russell DW. Molecular cloning: a laboratory manual. 3rd ed. Cold Spring Harbor: Cold Spring Harbor Laboratory Press; 2001

\section{Submit your next manuscript to BioMed Central and we will help you at every step:}

- We accept pre-submission inquiries

- Our selector tool helps you to find the most relevant journal

- We provide round the clock customer support

- Convenient online submission

- Thorough peer review

- Inclusion in PubMed and all major indexing services

- Maximum visibility for your research

Submit your manuscript at www.biomedcentral com/submit 